\title{
Research Progress in Gas Separation Using Hollow Fiber Membrane Contactors
}

\author{
Linlin Li ${ }^{1}$, Guiyang Ma ${ }^{1}$, Zhen Pan ${ }^{1}$, Na Zhang ${ }^{2}$ and Zhien Zhang ${ }^{3, *} \mathbb{0}$ \\ 1 College of Petroleum Engineering, Liaoning Shihua University, Fushun 113001, China; \\ linlin20200321@163.com (L.L.); guiyangma1@163.com (G.M.); Zhenpan_fs@126.com (Z.P.) \\ 2 Shandong Gas Marketing Branch, Sinopec Gas Company, Jinan 250000, China; NaaZhang@hotmail.com \\ 3 William G. Lowrie Department of Chemical and Biomolecular Engineering, The Ohio State University, \\ Columbus, $\mathrm{OH} 43210$, USA \\ * Correspondence: zhang.4528@osu.edu
}

Received: 5 October 2020; Accepted: 26 November 2020; Published: 29 November 2020

\begin{abstract}
In recent years, gas-liquid membrane contactors have attracted increasing attention. A membrane contactor is a device that realizes gas-liquid or liquid-liquid mass transfer without being dispersed in another phase. The membrane gas absorption method combines the advantages of chemical absorption and membrane separation, in addition to exhibiting high selectivity, modularity, and compactness. This paper introduces the operating principle and wetting mechanism of hollow membrane contactors, shows the latest research progress of membrane contactors in gas separation, especially for the removal of carbon dioxide from gas mixtures by membrane contactors, and summarizes the main aspects of membrane materials, absorbents, and membrane contactor structures. Furthermore, recommendations are provided for the existing deficiencies or unsolved problems (such as membrane wetting), and the status and progress of membrane contactors are discussed.
\end{abstract}

Keywords: membrane contactor; gas separation; $\mathrm{CO}_{2}$ capture; absorbent; membrane wetting

\section{Introduction}

Owing to the rapid economic development since the 20th century, the climate and environment have continued to deteriorate. Natural phenomena such as the greenhouse effect and acid rain are closely related to industrial production and energy use [1-5]. According to data from the National Oceanic and Atmospheric Administration/Earth System Research Laboratory, global $\mathrm{CO}_{2}$ emissions are steadily increasing, and the $\mathrm{CO}_{2}$ concentration in the atmosphere has reached $411 \mathrm{ppm}$, a new record high [6]. Further, the concentrations of atmospheric and other gases have increased, resulting in the greenhouse effect and the acidification of ecosystems, which has caused significant losses to the construction industry, agriculture, and public facilities. Studies have shown that fossil fuels including coal, oil, and natural gas will still dominate the energy structure in the short term [7]. Therefore, the Organization for Economic Cooperation and Development (OECD) countries and China have formulated increasingly strict regulations and laws to limit gas emissions to ensure the sustainable consumption of fossil energy [8,9]. So, the main content of this review is focused on the progress of membrane contactors in the field of gas separation, such as $\mathrm{CO}_{2}$ removal from coalbed methane, flue gas, and natural gas.

Advanced gas separation technology is important to satisfy the market demand for efficient and affordable sulfur emission control. Existing gas separation technologies include the physical adsorption method, low-temperature phase separation, chemical absorption, and membrane absorption methods. Traditional gas separation is primarily achieved by direct gas-liquid contact methods, such as using packed towers, spray towers, bubble towers, and other equipment, as shown in Figure 1. Membrane 
absorption has been developed for gas separation in recent years. A promising carbon dioxide removal process, it combines the selectivity of chemical absorption and the compactness of membrane separation. The interface area of the membrane contactor is approximately 30 times that of the conventional gas absorber, which can reduce the size of the absorber by 10 times [10].

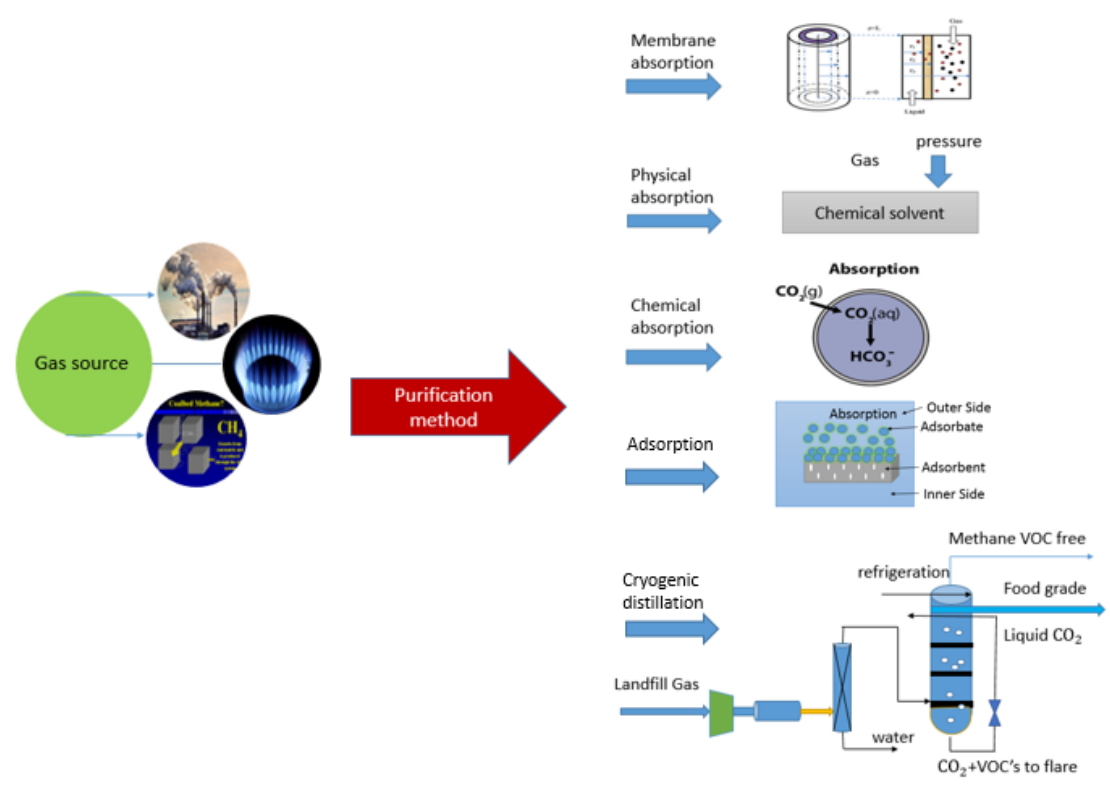

Figure 1. Classifications of gas treatment methods.

Membrane materials can be primarily classified into organic polymer membranes, inorganic membranes, and organic-inorganic composite membranes. Polypropylene (PP) [11], polyvinylide-nefluoride (PVDF) [12], polytetrafluoroethylene (PTFE) [13], polysulfone (PS) [14], polyethersulfone (PES) [15], and polyimide (PI) [16] are some of the most widely used membrane materials. In recent years, ceramic membranes have become a hot research topic owing to their high temperature resistance, strong thermal and chemical stability, and low energy consumption [17], however, their cost is relatively high. In addition, researchers recently discovered that membrane modification treatment is an effective and economical method to improve membrane performance, and matrix and surface modifications are the two main methods to modify the membrane.

The study of absorbents has always been the focus of hollow fiber membrane contactors (HFMCs) in the field of gas separation. Since the advent of membrane absorption technologies, researchers have conducted extensive studies on absorbents. Absorbents have been developed from pure water and $\mathrm{NaOH}$ [18] to alcohol amine [19], and gradually progressed to amino acid solutions [20], nanofluids [21], ionic fluids [22], etc. This research field is very rich, encompassing the subjects of chemistry, physics, molecular science, thermodynamics, and various other disciplines. The analysis and interpretation of some of the membrane absorption mechanisms inevitably produce numerous inconsistencies. This study points out the relevant contradictions and contrarian views. For reconciling these diverse views, more in-depth theoretical research and visual experiments aimed at understanding these mechanisms are needed.

Membrane wetting has always been a major obstacle in the development of membrane absorption methods. With an increase in the operating time, wetting of the membrane pores is often unavoidable. Even a small extent of membrane wetting has serious adverse effects on the gas separation efficiency. Researchers have attempted various methods to extend the time required for membrane wetting. The main methods are membrane material modification, absorbent improvement, and membrane structure improvement. This review introduces the mechanisms of membrane wetting and summarizes three types of wetting. The differential equations in the wet state and the boundary conditions needed 
to establish a model for the absorption mechanism will allow future researchers to study membrane wetting more effectively.

\section{Membrane Contactor Operating Principle and Wetting Mechanism}

\subsection{Operating Pathway}

In gas separation, the most widely used membrane module, i.e., hollow fiber membrane, has become a popular research topic. Herein, a hollow fiber membrane is used as an example to introduce its operating principle and wetting mechanism. The membrane contactor involves three processes for separating gas: a. the separated gas in the mixed gas is driven by the concentration difference to reach the membrane hole; $b$. the gas is transmitted to the gas-liquid interface through membrane pore diffusion; $c$. the gas crosses the gas-liquid interface and reacts with the liquid phase. The operating principle is shown in Figure 2.

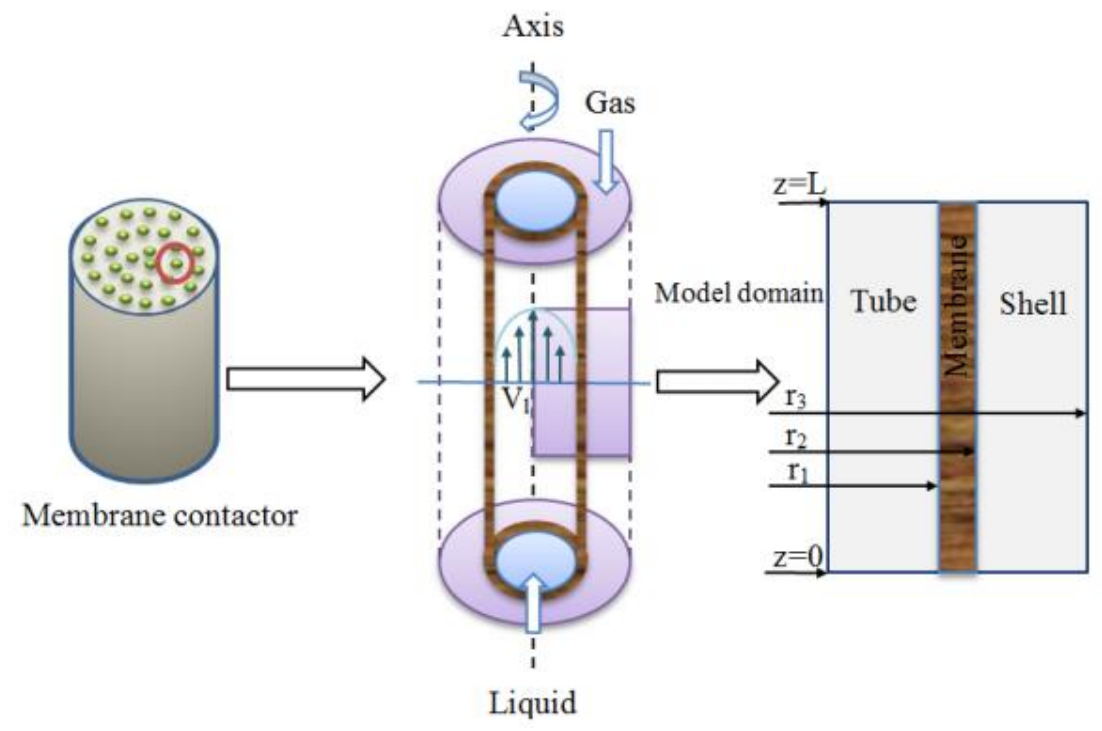

Figure 2. Operating principle of membrane absorption method [5].

When removing typical gases, the mass transfer resistance of the membrane contactor includes liquid-phase, gas-phase, and membrane resistances. According to the principle of parallel resistance, the total mass transfer resistance formula is as shown in Equation (1) [23]:

$$
\frac{1}{K_{G}}=\frac{1}{k_{g}}+\frac{1}{k_{m}}+\frac{1}{m \beta k_{1}}
$$

where $\frac{1}{K_{G}}$ is the total mass transfer resistance; $\frac{1}{k_{g}}$ is the gas phase resistance; $\frac{1}{k_{m}}$ is the membrane resistance; $m$ is the liquid-phase mass transfer coefficient; $\beta$ is the phase equilibrium constant; and $k_{1}$ is the chemical enhancement factor.

\subsection{Wetting Mechanism}

A large number of studies have shown that a slight membrane wettability can cause the membrane phase resistance to increase rapidly, which consequently increases the total mass transfer resistance and causes a significant decrease in mass transfer rate [24-31]. Rangwala et al. indicated that when the membrane has a small degree of wetting $(<2 \%)$ [32], the membrane resistance will increase rapidly, accounting for approximately $60 \%$ of the total mass transfer resistance. Therefore, preventing or reducing the wetting of the membrane contactor during operation is key to the industrialization of the membrane contactor. The wetting of membrane pores is an important factor hindering the 
development of membrane absorption methods. There are three cases of membrane wetting, as shown in Figure 3, which are non-wetting, partial wetting, and full wetting.

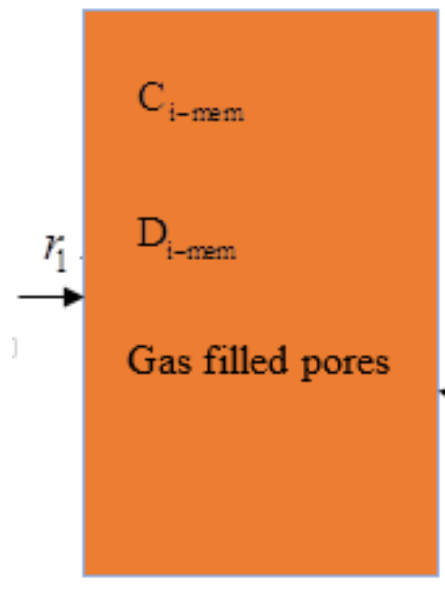

(a)

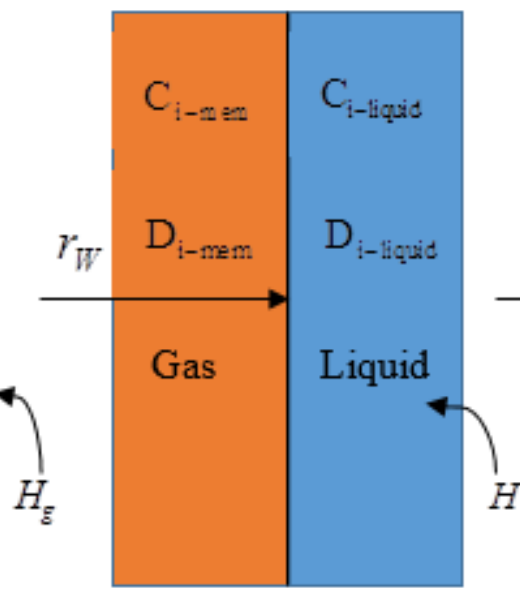

(b)

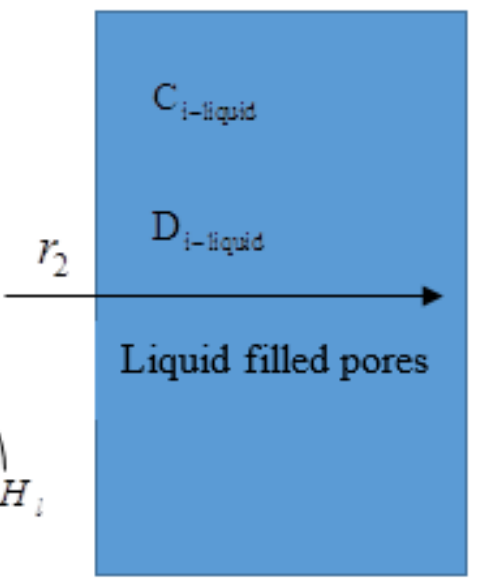

(c)

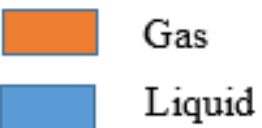

Figure 3. Schematic diagram of three wetting states. (a) Non-wetted, (b) partially wetted, and (c) fully wetted conditions.

\subsubsection{Non-Wetting Mode}

When a membrane is not wetted, the gaseous phase directly passes through the membrane pores. During this time, the membrane pores are filled with the gaseous phase, the mass transfer rate is the highest, and the reaction rate is the fastest, as shown in Figure 3a. Generally, researchers in this field assume the model to be in this state when studying the effects of related parameters. The simplified overall equation is given by Equation (2):

$$
-\left(\frac{1}{r} \frac{\partial\left(r\left(C_{i} V\right)_{r}\right)}{\partial r}+\frac{1}{r} \frac{\partial\left(C_{i} V\right)_{\theta}}{\partial \theta}+\frac{1}{r} \frac{\partial\left(C_{i} V\right)_{Z}}{\partial Z}\right)-\left(\frac{1}{r} \frac{\left(r\left(\partial J_{i}\right)_{r}\right)}{\partial r}+\frac{1}{r} \frac{\left(\partial J_{i}\right)_{\theta}}{\partial \theta}+\frac{\left(\partial J_{i}\right)_{Z}}{\partial Z}\right)+R_{i}=0
$$

The material balance in the membrane considers only the diffusion of the gas within the membrane pores, expressed as Equation (3) [33,34]:

$$
\frac{\partial C_{i-m e m}}{\partial t}+D_{i-m e m}\left[\frac{\partial^{2} C_{i-m e m}}{\partial r^{2}}+\frac{1}{r} \frac{\partial C_{i-m e m}}{\partial r}+\frac{\partial^{2} C_{i-m e m}}{\partial z^{2}}\right]=0
$$

where $D_{i-m e m}$ and $C_{i-m e m}$ are the molecular diffusivity and concentration distribution of component $\mathrm{i}$ in the gas phase within the membrane, respectively.

\subsubsection{Partially Wetted Mode}

For the partially wetted mode, there are two phases in the membrane pores-the gas-filled and liquid-filled phases-as shown in Figure $3 b$. In the gas-filled phase, the material balance can be derived using Equation (4) [33,34]:

$$
D_{i, g-\text { mem }}\left(\frac{\partial^{2} C_{i, g-m e m}}{\partial r^{2}}+\frac{1}{r} \frac{\partial C_{i, g-m e m}}{\partial r}+\frac{\partial^{2} C_{i, g-\text { mem }}}{\partial z^{2}}\right)=0
$$


In the case of partial wetting, the mass transfer equation of the liquid phase on the membrane side is given by Equation (5):

$$
D_{i, l-m e m}\left(\frac{\partial^{2} C_{i, l-m e m}}{\partial r^{2}}+\frac{1}{r} \frac{\partial C_{i, l-m e m}}{\partial r}+\frac{\partial^{2} C_{i, l-m e m}}{\partial z^{2}}\right)=0
$$

\subsubsection{Fully Wetted Mode}

The fully wetted model implies that the liquid phase completely fills the membrane pores. At this time, all the membrane pore volumes are occupied by the liquid, and the mass transfer rate is the lowest, as shown in Figure 3c. In this model, the material balance can be obtained from Equation (6):

$$
D_{i, l-m e m}\left(\frac{\partial^{2} C_{i-m e m}}{\partial r^{2}}+\frac{1}{r} \frac{\partial C_{i-m e m}}{\partial r}+\frac{\partial^{2} C_{i-m e m}}{\partial z^{2}}\right)=0
$$

where $D_{i, l-m e m}$ and $C_{i-m e m}$ are the molecular diffusivity and concentration of component $i$ in the liquid-filled phases within the membrane, respectively.

When the membrane pores are fully wetted, the penetration pressure of the solution in the liquid phase region is the minimum pressure at which the liquid absorbent enters the membrane pores. Its value can be evaluated by Laplace's equation (Equation (7)):

$$
L E P=\frac{-4 \gamma \cos \theta}{d_{\max }}
$$

where $\gamma$ is the surface tension of absorbent, $\theta$ is the contact angle between the solvent and membrane surface, and $d_{\max }$ the inner diameter of the largest membrane pore. Therefore, methods for preventing the wetting of the film include using a solvent with surface tension, or a method using a hydrophobic film material. The wetting of the membrane material begins at larger membrane pores. As time progresses, the smaller membrane pores gradually begin to wet until they are completely wet, as shown in Figure 3c. Therefore, it is extremely important to obtain a film material with a large contact angle and a solvent with a large surface tension to resist membrane wetting.

\section{Influencing Factors of Gas Separation in Membrane Contactors}

\subsection{Membrane Material}

The membrane material acts as a barrier that separates the gas phase from the liquid phase and has no selectivity. It primarily depends on the gas-phase selective absorption by the liquid-phase absorbent to achieve a mixed gas separation. The structure and properties of the membrane material determine the maximum membrane pore size and the two-phase contact angle. Since most of the absorbents used for separation and other gases are organic solvents, the surface tension of organic solvents is often low, which is prone to problems such as membrane wetting and increased mass transfer resistance. To solve these problems, many scholars have carried out improvements to membrane materials, and have achieved many results. The following sections describe the research progress of polymer membranes and ceramic membranes.

\subsubsection{Research Progress of Polymeric Membrane}

Membranes are commonly classified into polymeric and ceramic membranes according to the material type [35]. Polymer membranes mainly include polysulfones, polyamides, polyimides, polyesters, etc. Organic membranes are widely used due to their wide range of materials, low manufacturing costs, and high assembly density of membrane components. Several works have been carried out to improve the performance in terms of membrane materials [36-38]. The main problems are still high performance, membrane wetting, and membrane fouling. 
The methods of processing the surface of the membrane mainly include blending modification, chemical grafting, surface coating, etc. The treated membrane has better separation performance and anti-wetting properties. Naim et al. added nonsoluble additives, such as lithium chloride, methanol, and phosphoric acid (PA) to a porous asymmetric polyetherimide (PEI) membrane to improve its physical properties [39]. Xu et al. fabricated an inorganic-organic fluorinated titania-silica $\left(\mathrm{fTiO}_{2}-\mathrm{SiO}_{3}\right) / \mathrm{PVDF}$ composite membrane via an in situ vapor-induced hydrolyzation process, incorporated with perfluorodecyltriethoxysilane (PFTS) grafting, followed by a hydrophobic modification. They found that the fabricated membrane exhibited a high $\mathrm{CO}_{2}$ absorption flux of $8.0 \times 10^{-3} \mathrm{~mol} \mathrm{~m}^{-2} \mathrm{~s}^{-1}$ compared to a pristine PVDF membrane, and it possessed high chemical resistance and hydrophobicity [40]. Ma et al. addressed the problem of membrane materials getting easily wetted owing to long-term soaking in chemical absorbents by grafting commercial PVDF membranes with an organosilane on the surface [41]. Chen et al. added hydrophobic materials to the inner coating to densify the inner layer; the more hydrophobic the inner coating is, the higher the viscosity of the coating. This delays the phase transition process and improves the wettability of the membrane [42]. Lee et al. modified the hydrophobicity of the surface by binding fluoroalkylsilane (FAS) with OH-groups and deploying hydrophobic chains on the opposite side [43].

\subsubsection{Research Progress of Ceramic Membrane}

As we all know, the price of polymer membrane is cheap, but it has to be replaced frequently due to swelling, which increases the operating cost. So, recent studies have focused on gas-liquid membrane contactors composed of a ceramic material with excellent thermal chemical stability and extraordinary mechanical strength [44-47].

Ceramic membranes have attracted attention because of their high separation efficiency, good chemical stability, acid and alkali resistance, organic solvent resistance, bacterial resistance, high temperature resistance, and pollution resistance. Common fabrication techniques of ceramic membranes include extrusion, pressing, slip casting, tape casting, sol-gel, phase inversion, anodic oxidation, and chemical vapor deposition (CVD) methods [35]. Currently, ceramic hollow fiber membranes are fabricated by combined phase-inversion/sintering in an asymmetric structure with unique finger-like and sponge-like structures [47]. Lee et al. fabricated ceramic hollow fiber membrane contactors (CHFMCs) using a phase inversion/spinning method, and the module consisted of 200 ceramic hollow fibers and was tested in different working conditions [48].

Due to having superior surface chemical properties compared to polymer membranes, ceramic membranes have become very common in the field of sewage treatment. Some researchers have also used them for gas separation in harsh environments. Ogunlude et al. used ceramic nanostructured membranes to separate gas from biogas, and the separation of $\mathrm{CH}_{4}$ from $\mathrm{CH}_{4} / \mathrm{CO}_{2}$ has achieved good performance, and the treated biogas can be used as alternative energy [49]. An et al. fabricated a superhydrophobic ceramic (SC) membrane contactor for capturing $\mathrm{CO}_{2}$ from coal-fired power plant flue gas. They found that the detrimental effects of wetting can be alleviated by periodic drying, and used two SC membrane contactors alternatively operated with periodic drying to ensure continuous $\mathrm{CO}_{2}$ removal with high efficiency [50].

For the wide application of membrane contactors, membrane fouling has been the bottleneck since the birth of membrane separation technology. There have been many reports on the membrane fouling mechanisms and fouling control strategies of polymers [51,52]. Changes in polymer membrane selectivity and flux of polymer membranes can be attributed to membrane fouling and microbial invasion, and concentration polarization and free chlorine attack [53]. However, there are no clear explanations of the membrane fouling mechanism of ceramic membranes [54]. Lee et al. employed the filtration models to analyze the fouling characteristics of ceramic membranes, which have been applied to polymeric membranes. They indicated that these models built on cake filtration could also be utilized to simulate natural organic matter (NOM) fouling of ceramic membranes, as shown in Figure 4a [55]. Zhao et al. elucidated the removal mechanisms governing pharmaceutically active 
compounds (PhACs) using four types of commercially available ceramic nanofiltration (NF) membranes and suggested that electrostatic interactions were more dominant than hydrophobic interactions due to higher hydrophilicity and lower densities of $\mathrm{COOH}$ and $\mathrm{OH}$ groups on the ceramic surface compared to the polymeric counterparts, as shown in Figure 4b [56]. However, this was only applicable when PhACs were spiked in deionized water. Hydrophobic interactions and adsorption played a major role when real wastewater effluent was used to form a fouling layer [35]. Therefore, further research on the mechanism governing the separation and fouling processes of ceramic NF membranes or fine UF membranes in real water treatment is needed.

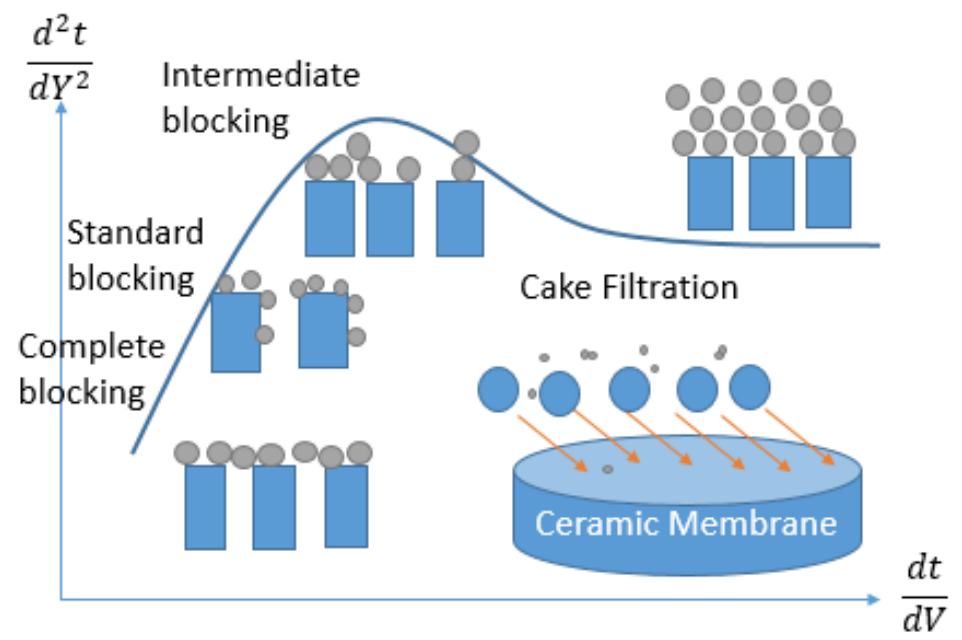

(a)

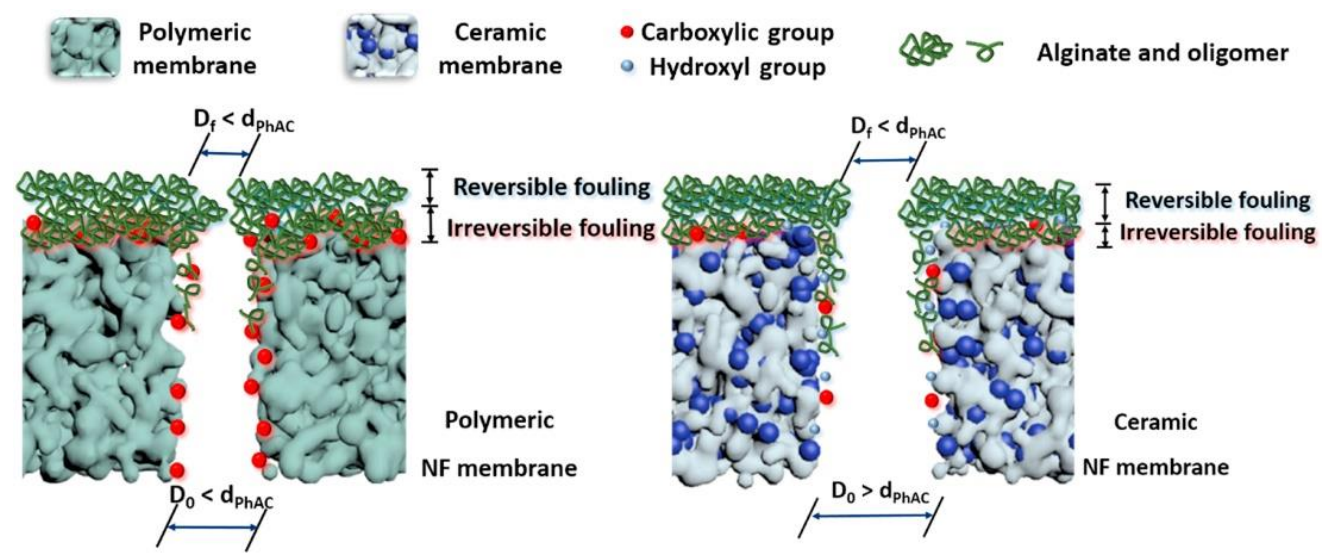

(b)

Figure 4. Schematic illustration of (a) fouling characteristics of ceramic membranes using filtration models [55] and (b) fouling of polymeric and ceramic nanofiltration membranes by alginate [56].

Table 1 lists the uses of different membrane materials for gas removal processes. 
Table 1. Summary of different membrane materials used for gas removal.

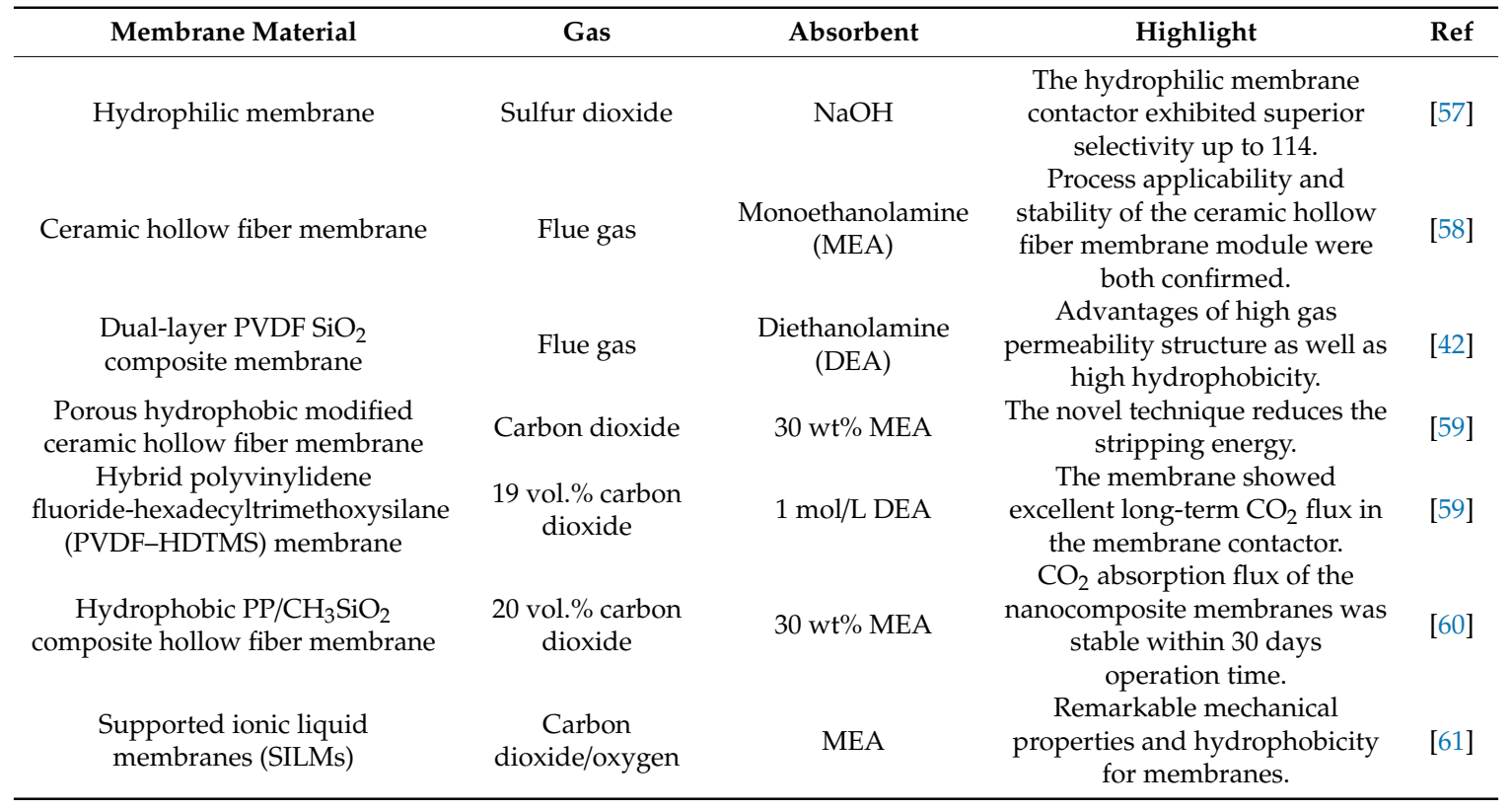

\subsection{Absorbents}

An absorbent is a solvent used in membrane contactors for chemical reactions with mixed gases to achieve gas separation. The selection of absorbent is crucial; properties such as recyclability, high surface tension, volatility, easy regeneration, being environmental friendly, and absorption efficiency must be considered [62]. Typical absorbents include monoethanolamine (MEA), diethanolamine (DEA), and methyldiethanolamine (MDEA). However, although alcohol amine solvents have the advantage of facilitating a fast absorption rate, the amine solutions have notable defects, such as thermal and oxidative degradation, equipment and pipeline corrosion, toxicity, and, most importantly, easy wetting of the membrane owing to the a low surface tension of the absorbent $[63,64]$. Therefore, researchers have been actively exploring various absorbents and their characteristics. Some of the main absorbents and their characteristics relevant to the current research are introduced below.

\subsubsection{Amine Solvent}

As alcohol amine solvents have a high capacity for gas absorption, and they have the characteristics of fast absorption rate, large absorption capacity, and simple regeneration. Currently, amine solvents are commercially available, and widely used and studied in practical applications. An alcohol amine solution developed from a single absorbent to a mixed absorbent improves the gas removal performance of a membrane. As there are a large number of literature reviews that have introduced the related research, it is not extensively covered here. However, the knowledge on active alcohol ammonium solvents is still relatively small. The following section introduces some of the latest developments in active alcohol ammonium solvents.

\subsubsection{Activated Alcohol Amine Solvent}

The activated alcohol amine solvent is an improved solvent by adding an activator to the original ammonia solution. In recent years, to improve the $\mathrm{CO}_{2}$ absorption performance, researchers have studied the mixing of active alcohol ammonium and alcohol amine solvents. Rahmawati et al. added piperazine (PZ) and monosodium glutamate (MSG) as activators at a $1 \% w / w$ concentration in a MDEA $30 \mathrm{wt} \%$ solution to form an aqueous solution of activated MDEA. Their results showed that MDEA-PZ was the best absorbent for $\mathrm{CO}_{2}$ with a separation efficiency 1.4 times higher than that of an inactive MDEA absorbent [65]. Saidi et al. studied the mass transfer of 1-dimethylamino-2-propanol as a new 
type of amino alcohol solvent in a split absorption tower-stripping unit. Their modeling indicated that the $\mathrm{CO}_{2}$ absorption flux and the overall mass transfer coefficient $\left(\mathrm{k}_{\mathrm{G}} \mathrm{a}_{\mathrm{V}}\right)$ for $\mathrm{CO}_{2}$ absorption in different solutions could be ranked as follows: $\mathrm{PZ}>\mathrm{MEA}>\mathrm{DEA}>$ 4-diethylamine-2-butanol (DEAB) $>$ 1-dimethylamino-2-propanol (1DMA2P) $>$ MDEA $>$ triethanolamine (TEA) [66]. These studies on active alcohol amine solutions had a positive impact on the application and development of alcohol amine solvents. However, more experimental verification and long-term running tests are needed for applying the above in industrial production.

\subsubsection{Amino Acid Solutions}

Amino acid solutions have the same functions as alcohol amine solvents; however, they also have other advantages. For example, they possess better oxidation stability and resistance to degradation, and can be nonvolatile after adding salt. As a result, they have proven themselves to be promising absorbents [67]. Yan et al. used a natural amino acid, potassium L-argininate (PA), as an absorbent in HFMCs to absorb $\mathrm{CO}_{2}$, and found that the $\mathrm{CH}_{4}$ content in biogas treated with PA could reach up to 99.15\% [34]. Compared with MEA, it has better applicability; furthermore, the PA solvent can use a lower solvent concentration, lower liquid velocity, and higher reaction temperature [68].

To achieve a higher reaction rate, the amino acid salt solution is often used in conjunction with other solutions. Jian et al. added PZ to a glycine solution and compared it with a single glycine acid solution. They found that the $\mathrm{CO}_{2}$ capture performance of the active glycinate solution was significantly better than that of the inactive glycinate solution. The average value of reaction rate in the activated solution was 1.3 times that of the inactive solution [69]. The amino acid solution can also be mixed with a salt solution (e.g., $\mathrm{K}_{2} \mathrm{CO}_{3}, \mathrm{~K}_{2} \mathrm{~B}_{4} \mathrm{O}_{7}$ ), to obtain many beneficial effects. Li et al. mixed lysine and potassium carbonate to absorb $\mathrm{CO}_{2}$. Their results showed that the optimal molar ratio of the $\mathrm{K}_{2} \mathrm{CO}_{3}$ solution was 5:5 (the total concentration of the absorbent was $1 \mathrm{M}$ ), which was 1.68 times the absorption load of the pure $\mathrm{K}_{2} \mathrm{CO}_{3}$ solution [70]. Feng et al. mixed arginine with potassium carbonate and the results showed that L-arginine not only significantly increased the rate of $\mathrm{CO}_{2}$ absorption by the potassium carbonate solution, but also increased the desorption rate by two-fold. Under the same conditions, the normalized mass transfer flux of $0.1 \mathrm{M}$ L-arginine activated potassium carbonate solution to absorb $\mathrm{CO}_{2}$ increased by approximately $85 \%$ [71]. Lu et al. added potassium borate as an activator to glycinate (GLY) aqueous solution to form an activated composite absorbent (ACA) for capturing $\mathrm{CO}_{2}$, and studied the effect of activator concentration, operating temperature, and adsorption flow rate on the total volume mass transfer. It was found that the $\mathrm{CO}_{2}$ capture efficiency of ACA was significantly higher than that of the GLY aqueous solution. It was also observed that the activation effect of a small amount of activator on the ACA was greater than that of a large number of activators [72].

\subsection{4. $\mathrm{K}_{2} \mathrm{CO}_{3}$}

Compared with traditional solutions, $\mathrm{K}_{2} \mathrm{CO}_{3}$ solution shows better thermal stability and lower regeneration costs, and can be considered as an appropriate absorbent alternative for $\mathrm{CO}_{2}$ separation . It is thermally more stable than alcohol amine solutions and can be employed in $\mathrm{CO}_{2}$ sequestration processes at high temperatures. The low regeneration cost of $\mathrm{K}_{2} \mathrm{CO}_{3}$, particularly at higher $\mathrm{CO}_{2}$ concentrations, makes it a reactive stripping absorbent for efficient $\mathrm{CO}_{2}$ capture from gaseous streams. In addition, the $\mathrm{K}_{2} \mathrm{CO}_{3}$ aqueous solution is non-organic, and has a high surface tension and low tendency for wetting the membrane contactor pores compared to alkanolamine absorbents. These advantages strongly justify the utilization of this absorbing solution [73].

A gas source typically contains more than a single gas. For example, untreated natural gas contains $\mathrm{CO}_{2}, \mathrm{H}_{2} \mathrm{~S}, \mathrm{CH}_{4}$, and other gases. It is necessary to remove all the gases at the same time. The requirements for the absorbent for the removal of two or more gases are often very high, and the absorbent is required to achieve a relatively high removal rate for all the gases. A single $\mathrm{K}_{2} \mathrm{CO}_{3}$ solvent is effective in removing $\mathrm{H}_{2} \mathrm{~S}$; however, its performance in removing $\mathrm{CO}_{2}$ is not very considerable. 
Although the reaction kinetics of $\mathrm{K}_{2} \mathrm{CO}_{3}$ and $\mathrm{CO}_{2}$ are very slow, amino acid salts can promote the chemical reaction of $\mathrm{K}_{2} \mathrm{CO}_{3}$. In addition, compared with amine solutions such as MEA, amino acid salts consume less renewable energy, which can reduce the cost of $\mathrm{CO}_{2}$ regeneration [5]. Therefore, researchers have investigated mixing these two types of absorbents with process gases.

$\mathrm{Li}$ et al. added amino acid salts to a $\mathrm{K}_{2} \mathrm{CO}_{3}$ solution. Their results showed that the use of amino acid salts (AASs) in the $\mathrm{K}_{2} \mathrm{CO}_{3}$ solution as an accelerator could significantly improve the $\mathrm{CO}_{2}$ absorption performance. They also compared the decarbonization effects of three amino acids. Of these, $\mathrm{K}_{2} \mathrm{CO}_{3}$ and potassium glycinate (PG) was the most effective, as shown in Figure 5 [74]. Zhang et al. found that the decarburization effect after adding potassium lysinate (PL) solvent to $\mathrm{K}_{2} \mathrm{CO}_{3}$ was better than that of a single $\mathrm{K}_{2} \mathrm{CO}_{3}$ solvent and concluded that the gas phase is the most important influencing factor [5].

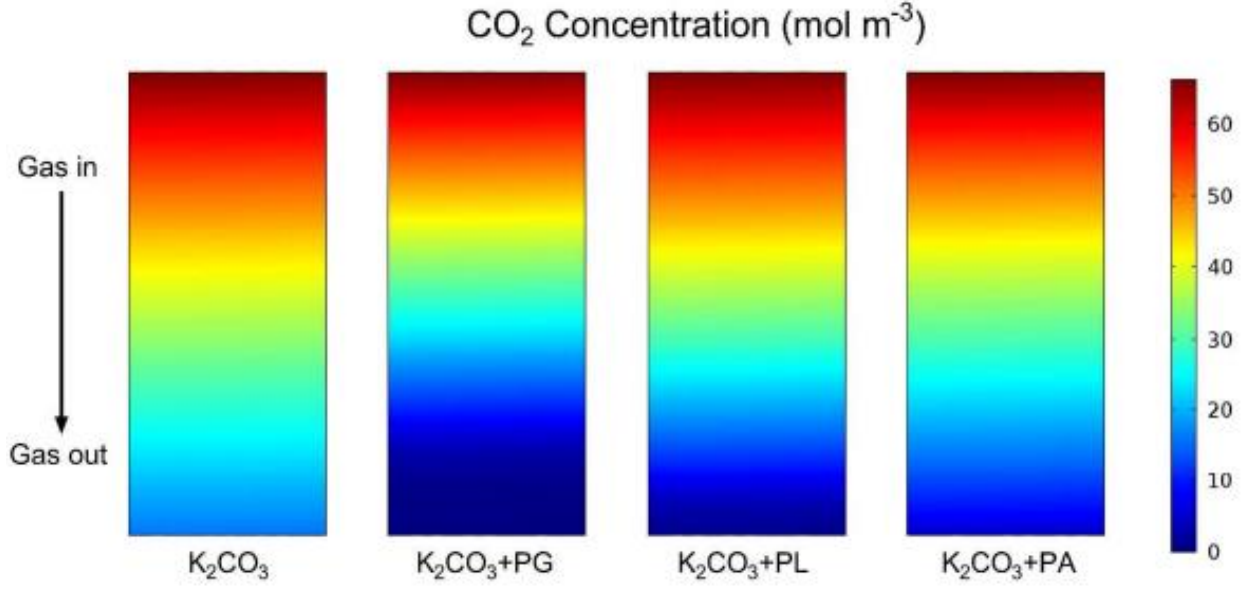

Figure 5. $\mathrm{CO}_{2}$ concentration distribution in the tube with different absorbents (absorption temperature: $313 \mathrm{~K}$; operating pressure: 4 bar; gas flow rate: $800 \mathrm{~mL} / \mathrm{min}$; and liquid flow rate: $75 \mathrm{~mL} / \mathrm{min}$ ) [74].

\subsubsection{Nanofluids}

Nanofluids are nanomaterials with a diameter of less than $100 \mathrm{~nm}$ and can be stably suspended in the liquid [75]. Nanofluids act as absorbents, causing the laminar flow of the traditional membrane contactor system to become turbulent [76]. Among the many nanoparticles used to prepare nanofluids, $\mathrm{Al}_{2} \mathrm{O}_{3}, \mathrm{SiO}_{2}$, and $\mathrm{CuO}$ are the most common. Pang et al. provided a comprehensive review of the mass transfer characteristics of nanofluids [77]. Three possible mechanisms for enhancing the mass transfer of nanofluids were proposed in the literature, which include (a) grazing (or shuttle) effect [62], (b) fracture effect due to bubbles [78], and (c) gas-liquid interface shape in hydrodynamic action [79], which increases the mass transfer interface. The schematic diagrams of these mass transfer mechanisms are illustrated in Figure 6.

In recent years, numerous studies have confirmed that nanofluids could significantly enhance the mass transfer rate. However, the inconsistencies among these research results and the lack of reliable mechanisms to explain these conflicting results indicate that more research is needed to clarify the impact of nanoparticles of different types on mass transfer in applications. Tinge et al. proposed a model considering the shuttle or grazing effect theory. The particles were supposed to transport an additional amount of gas to the liquid bulk through adsorption in the gas-liquid diffusion layer and desorption in the liquid bulk, which resulted in a larger mass transfer coefficient [78]. Kim et al. proposed the bubble breaking model to explain the anomalous enhancement in mass transfer with visualization experiments. They reported that the detachment of the gas bubbles in nanofluids occurred during a much shorter period of time than in the base fluid; the faster detachment led to a higher frequency rate, as reported in the literature, thus yielding a smaller bubble size with an increased bubble quantity [79]. Yoon et al. demonstrated the two-film theory: the gas-liquid film interface 
controls resistance to the transfer of a material from one phase to another. It diffuses through the gas film and proceeds at a rate that is proportional to the difference between solute concentrations in the gas on the outside and inside of the gas film, while the diffusion through the liquid film is controlled by the difference between the concentration of solute in the liquid at the interface and its concentration on the other side of the liquid film [80]. According to these three explanations, when the nanoparticle concentration increases, the mass transfer rate should increase. However, several studies showed that when nanoparticles increased to a certain extent, the mass transfer showed a tendency to decrease [81-83]. Therefore, more studies are needed on the mass transfer mechanism of nanofluids.

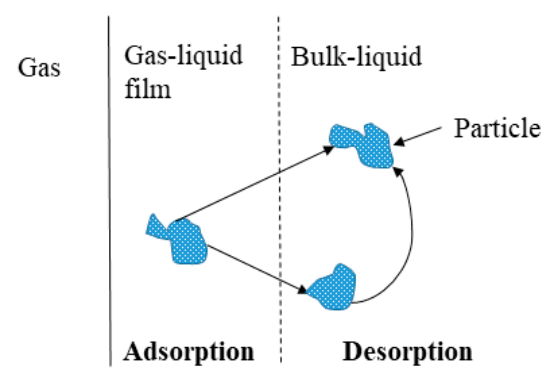

(a)

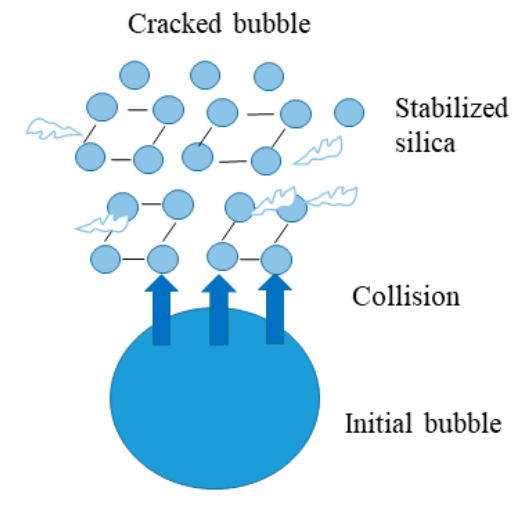

(b)
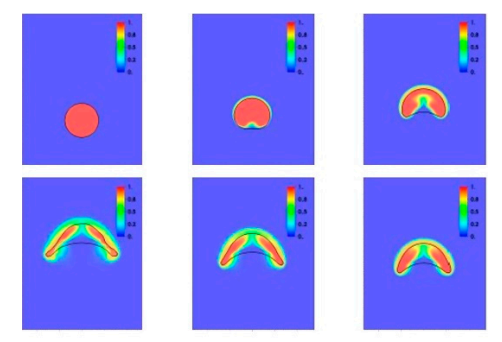

Water- $-\mathrm{CO}_{2}$
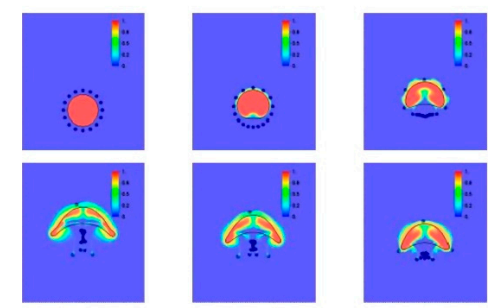

Water- $\mathrm{CO}_{2}+16 \mathrm{Al}_{2} \mathrm{O}_{3}$

(c)

Figure 6. (a) Grazing (or shuttle) effect [78]; (b) mass transfer interface increase by bubble breaking effect [79]; (c) gas-liquid interface shape in hydrodynamic effect [80]. 
Krishnamurthy et al. studied the effect of water-based nanofluids containing $20 \mathrm{~nm} \mathrm{Al}_{2} \mathrm{O}_{3}$ nanoparticles on the mass diffusion of fluorescent dyes and found that the diffusion coefficient in nanofluids was 13 times that of water without the nanoparticles [84]. Ansaripour et al. also confirmed this finding by using $\alpha-\mathrm{Al}_{2} \mathrm{O}_{3} /$ water and $\gamma-\mathrm{Al}_{2} \mathrm{O}_{3} /$ water nanofluids with a nano-porous hollow fiber dialysis membrane contactor to remove $\mathrm{CO}_{2}$ from $\mathrm{N}_{2} / \mathrm{CO}_{2}$ gas mixtures. The results showed that the increases in the removal efficiency of $\alpha-\mathrm{Al}_{2} \mathrm{O}_{3} /$ water and $\gamma-\mathrm{Al}_{2} \mathrm{O}_{3} /$ water nanofluids with a concentration of $0.02 \mathrm{vol} \%$ in comparison with distilled water were $12.2 \%$ and $21.6 \%$, respectively [85]. Olle et al. used functional magnetic nanoparticles to enhance oxygen mass transfer and found that it was increased up to six-fold by a water-based $\mathrm{Fe}_{3} \mathrm{O}_{4}$ nanofluid [86]. These studies have proved the enhancement effect of nanoparticles on mass transfer and gas removal. However, some studies have not achieved positive results. Sumin et al. obtained contradictory results. They found that micron-sized $\mathrm{Al}_{2} \mathrm{O}_{3}$ had no effect. While nano- $\mathrm{Al}_{2} \mathrm{O}_{3}$ enhances the weak absorption of $\mathrm{CO}_{2}$, activated carbon (AC) and carbon nanotube (CNT) particles effectively improve the gas-liquid mass transfer [87]. Therefore, although current research results usually show that these particles benefit the gas separation, it is still difficult to judge their performance in large-scale applications, and more research is needed in this area. For example, the role of nanoparticles in the presence of chemical absorbents is still questionable.

To date, there have been some studies suggesting that nanofluids have certain anti-wetting properties. Talavari et al. found from a long-term absorption test that membranes showed a tendency toward non-wetting, and the membrane pores in a nanofluid absorbent were not blocked [88]. However, their study lacked theoretical support, and there were no comparative experiments to substantiate their claims. Therefore, it remains to be verified whether nanofluids exhibit resistance to moisture.

The characteristics of these absorbents are shown in Table 2.

Table 2. Types and characteristics of absorbents.

\begin{tabular}{|c|c|c|c|c|}
\hline Absorbent Type & Main Solvents & Advantages & Disadvantages & Ref. \\
\hline \multirow[b]{2}{*}{ Alcohol amine solvent } & DEAB & Low energy consumption for degradation & $\begin{array}{l}\text { Easily cause corrosion to } \\
\text { equipment, easy to } \\
\text { degrade and easy to wet }\end{array}$ & [90] \\
\hline & $\begin{array}{l}\text { 1-dimethylamino-2-propanol } \\
\text { (1DMA2P) }\end{array}$ & $\begin{array}{l}\text { High } \mathrm{CO}_{2} \text { absorption capacity, } \\
\text { regeneration energy of } 1 \mathrm{DMA} 2 \mathrm{P} \text { is lower } \\
\text { than that of MDEA, DEA, MEA, and PZ }\end{array}$ & $\begin{array}{l}\text { High volatility of } \\
\text { DMAPA and substantial } \\
\text { energy requirement }\end{array}$ & [91] \\
\hline \multirow{2}{*}{ Nanofluid absorbent } & $\mathrm{Al}_{2} \mathrm{O}_{3}$ & \multirow{2}{*}{$\begin{array}{l}\text { Increased diffusion coefficient and } \\
\text { increased reaction rate }\end{array}$} & \multirow{2}{*}{$\begin{array}{l}\text { High viscosity and high } \\
\text { cost }\end{array}$} & \multirow{2}{*}{ [88] } \\
\hline & $\mathrm{SiO}_{2}$ & & & \\
\hline $\mathrm{K}_{2} \mathrm{CO}_{3}$ & $\mathrm{~K}_{2} \mathrm{CO}_{3}$ & $\begin{array}{l}\text { High surface tension with low tendency } \\
\text { to membrane wetting thermal stability, } \\
\text { low regeneration cost }\end{array}$ & $\begin{array}{l}\text { High energy } \\
\text { consumption, high heat } \\
\text { capacity, strong corrosive }\end{array}$ & [93] \\
\hline \multirow[t]{3}{*}{$\begin{array}{l}\text { Amino acid solutions } \\
\text { (AASs) }\end{array}$} & Potassium lysinate (PL) & $\begin{array}{l}\text { High gas absorption capacity, and has a } \\
\text { higher chemical reactivity to } \mathrm{CO}_{2}\end{array}$ & \multirow{3}{*}{$\begin{array}{l}\text { The reaction rate with } \\
\mathrm{CO}_{2} \text { is slow, generally } \\
\text { mixed with other } \\
\text { solutions for use }\end{array}$} & [87] \\
\hline & Potassium sarcosine (PS) & Thermal stability and easy regeneration & & [94] \\
\hline & Potassium glycinate (PG) & $\begin{array}{l}\text { High reactivity toward } \mathrm{CO}_{2} \text { and less } \\
\text { regeneration energy consumption }\end{array}$ & & [95] \\
\hline Ionic liquids (ILs) & 1 & $\begin{array}{l}\text { Negligible volatility, high thermal } \\
\text { stability, adjustability, solvation, high } \\
\qquad \mathrm{CO}_{2} \text { solubility }\end{array}$ & $\begin{array}{l}\text { High cost, high viscosity, } \\
\text { and high energy } \\
\text { consumption in the } \\
\text { regeneration process }\end{array}$ & [96] \\
\hline
\end{tabular}

\subsection{Contactor Structure}

It is more typical to increase the separation rate by changing the internal structure of the membrane contactor. Generally, a baffle is added inside the membrane contactor to achieve the second reflux of the gas, or a double-sleeve structure is used to improve the absorption efficiency. The occurrence 
of some undesirable phenomena in the separation process can be reduced by using shell ditch flow. Zhang et al. discovered that adding baffles in the membrane contactor can effectively reduce the shell-side groove flow phenomenon often discovered in experiments [97]; additionally, it can promote the liquid-phase flow in the tube and the two-phase mass transfer along the membrane, thereby improving the separation effect of membrane packing. Yang et al. used seven methylsiloxane-coated hollow fiber membranes as structural fillers. In the ethanol-water solution separation, two baffles were installed on the shell side of the membrane contactor [98]. The results show that the baffle assists the membrane module in obtaining a higher mass transfer coefficient and a smaller mass transfer resistance, especially at higher steam speeds. Zhang et al. adopted an improved double-sleeve hollow fiber membrane contactor for removing ammonia from an aqueous solution under a low-absorption liquid concentration and a low-absorption liquid flow rate [99]. The overall mass transfer coefficient of this improved double-sleeve hollow fiber membrane contactor is much higher than that of the single membrane module; under the same experimental conditions, its special configuration reduces the dilution of the byproduct ammonium salt solution by osmotic distillation and the byproduct ammonium sulfate. The concentration is approximately $9 \%$ higher than that of the single membrane module. Wang et al. studied the concept of a dual membrane system, in which a second membrane was added to the single membrane system [100], and a purge gas or a lower applied pressure on the permeate side of the porous or nonporous secondary membrane. The effect of a double film was analyzed theoretically. It is theoretically believed that the new model will obtain better absorption liquid regeneration effects and higher gas removal efficiency, as shown in Figure 7.

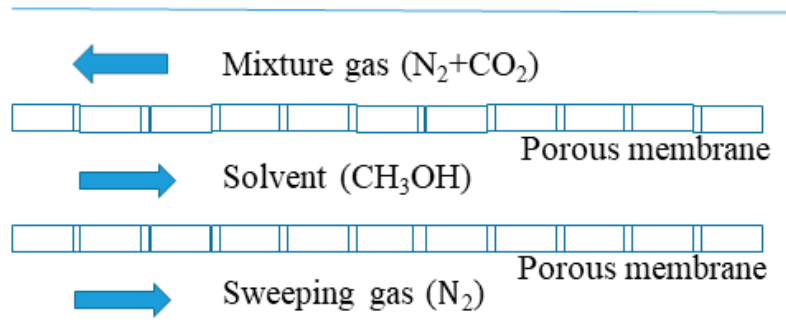

Figure 7. Schematic arrangements of membranes in the proposed novel dual-membrane system [100].

\subsection{Others}

In the membrane contactor, other parameters affect gas separation. For example, increasing the module length, membrane porosity, gas flow rate, liquid flow rate, and other parameters can change the gas separation efficiency. In actual production, reasonable parameters will significantly improve gas separation efficiency. The parameters affecting the separation performance of the membrane contactor are discussed below.

A large number of studies have shown that increasing the absorbent flow rate and concentration, reducing the gas flow rate, and reducing the volume fraction of the separated gas in the mixed gas are conducive to gas purification [10,101-104]. When the flow rate of an absorbent is increased, the diffusion rate of the liquid phase will increase. This is due to the increase in the liquid flow rate, which increases the pressure difference between the gas and liquid phases, and further increases the reaction rate. Tahvildari et al. established a gas-liquid chemical reaction and mass transfer model using 2-amino-2-methyl-1-propanol (AMP) as an absorbent in HFMCs. The results obtained by the effective element method were consistent with the experimental data: increasing the solvent flow rate can promote the removal of the hollow fiber membrane contactor pairs; the countercurrent process was more conducive to achieving the highest separation efficiency [105]. Nakhjiri et al. discovered that increasing the operating parameters, such as module length, membrane porosity, and absorbent concentration, can increase the removal rate in the gas mixture [106], however, the increase affected the separation efficiency negatively. Majid found that increasing the temperature enhanced the $\mathrm{CO}_{2}$ absorption and, although increasing the temperature decreased the $\mathrm{CO}_{2}$ solubility in the liquid phase, 
it improved the reaction rate and diffusion coefficients, as illustrated in Figure 8 [107]. Zhang et al. also studied the effect of gas pressure on the removal efficiency and flux, as shown in Figure 9 [108]. It can be seen that as the pressure increased, both the removal efficiency and $\mathrm{CO}_{2}$ flux increased.

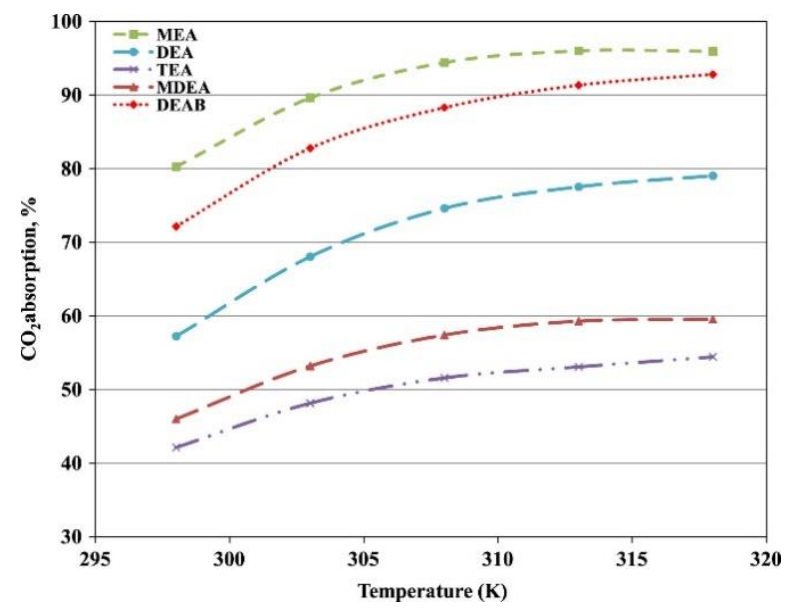

Figure 8. Effect of temperature on $\mathrm{CO}_{2}$ absorption for various absorbents under the non-wetting condition $\left(\mathrm{CO}_{2}: 20 \% ; \mathrm{N}_{2}: 80 \%\right.$; gas velocity: $0.2 \mathrm{~m} / \mathrm{s}$, liquid velocity: $0.01 \mathrm{~m} / \mathrm{s}$; absorbent concentration: $1 \mathrm{M}$; pressure: $120 \mathrm{kPa}$ ) [107].

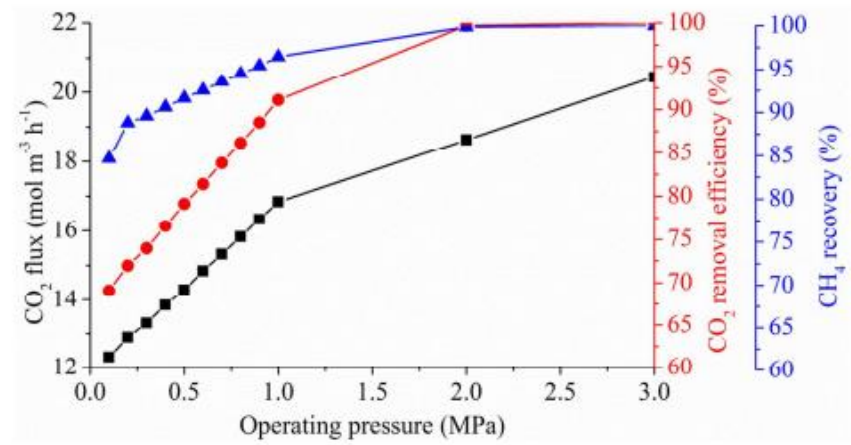

Figure 9. Effect of operating pressure on the hollow fiber membrane contactor (HFMC) performance for various absorbents (initial $\mathrm{CO}_{2}$ concentration: $40 \%$; PA concentration: $5 \mathrm{wt} \%$; gas velocity: $0.32 \mathrm{~m} / \mathrm{s}$; liquid velocity: $0.06 \mathrm{~m} / \mathrm{s}$ ) [108].

Studies based on the influences of membrane materials, absorbents, and membrane structures are important for evaluating the gas separation performance in membrane contactors, which can provide important judgments for the future research and development of membrane contactors.

\section{Conclusions and Future Perspectives}

This review primarily summarizes the working principle of a membrane contactor and the differential equations under the three states of membrane wetting. It also introduces the state of the art in membrane materials and the main improvement methods of membrane materials, including blending modification, surface coating, and surface treatment. These three methods differ in their characteristics and applications. With regard to absorbents, this review enumerates some widely used absorbents, summarizes their characteristics, and discusses the shortcomings of previously published papers in this field. Moreover, this study presents the structure effect of a membrane contactor on gas separation. Modifications to the membrane structure are helpful in improving the gas separation efficiency; however, large-scale commercial applications need to be further investigated. The influence of other parameters is also very significant for further research in this field, specifically, 
those that serve as index parameters for judging the quality of the absorbents, membrane materials, and membrane structures.

The direction of the future development of membrane contactors is still the improvement of membrane materials and the renewal of absorbents, because membrane wetting is still the main obstacle of the membrane gas absorption method. In addition, in the process of comprehensive research on practical applications, the evaluation of economic benefits can be added to the process, and the most common recycling systems should also be discussed and studied. This helps to achieve practical applications of the membrane contactors faster. In a word, the membrane contactor is a promising gas separation tool and deserves more attention.

Author Contributions: Conceptualization, G.M. and Z.P.; methodology, Z.Z. and N.Z.; writing-original draft preparation, L.L. All authors have read and agreed to the published version of the manuscript.

Funding: Liaoning Provincial Doctoral Research Startup Fund Project (2019-BS-159) and Liaoning Provincial Department of Education Key Research Project (L2020002).

Conflicts of Interest: The authors declare no conflict of interest.

\section{References}

1. Zhang, N.; Pan, Z.; Zhang, Z.; Zhang, W.; Zhang, L. $\mathrm{CO}_{2}$ capture from coalbed methane using membranes: A review. Environ. Chem. Lett. 2020, 18, 79-96. [CrossRef]

2. Dagan-Jaldety, C.; Fridman-Bishop, N.; Gendel, Y. Nitrate hydrogenation by microtubular CNT-made catalytic membrane contactor. Chem. Eng. J. 2020, 401, 126142. [CrossRef]

3. Nieminen, H.; Järvinen, L.; Ruuskanen, V.; Laari, A.; Ahola, J. Mass transfer characteristics of a continuously operated hollow-fiber membrane contactor and stripper unit for $\mathrm{CO}_{2}$ capture. Int. J. Greenh. Gas Control 2020, 98, 103063. [CrossRef]

4. Cabezas, R.; Prieto, V.; Plaza, A.; Merlet, G.; Quijada-Maldonado, E.; Torres, A.; Yáñez-S, M.; Romero, J. Extraction of vanillin from aqueous matrices by membrane-based supercritical fluid extraction: Effect of operational conditions on its performance. Ind. Eng. Chem. Res. 2020, 59, 14064-14074. [CrossRef]

5. Pan, Z.; Zhang, N.; Zhang, W.; Zhang, Z. Simultaneous removal of $\mathrm{CO}_{2}$ and $\mathrm{H}_{2} \mathrm{~S}$ from coalbed methane in a membrane contactor. J. Clean. Prod. 2020, 273, 123107. [CrossRef]

6. Zhang, Z.; Pan, S.-Y.; Li, H.; Cai, J.; Olabi, A.G.; Anthony, E.J.; Manovic, V. Recent advances in carbon dioxide utilization. Renew. Sustain. Energy Rev. 2020, 125, 109799. [CrossRef]

7. Algarini, A.; Ozturk, I. The relationship among GDP, carbon dioxide emissions, energy consumption, and energy production from oil and gas in Saudi Arabia. Int. J. Energy Econ. Policy 2020, 10, 280-285. [CrossRef]

8. Wang, Z.S.; Pan, L.-B. Implementation results of emission standards of air pollutants for thermal power plants: A numerical simulation. Environ. Sci. 2014, 35, 853-863.

9. Wang, B.; Lau, Y.S.; Huang, Y.; Organ, B.; Ho, K.F. Investigation of factors affecting the gaseous and particulate matter emissions from diesel vehicles. Air Qual. Atmosph. Health 2019, 12, 1113-1126. [CrossRef]

10. Rosli, A.; Ahmad, A.L.; Low, S.C. Enhancing membrane hydrophobicity using silica end-capped with organosilicon for $\mathrm{CO}_{2}$ absorption in membrane contactor. Sep. Purificat. Technol. 2020, 251, 117429. [CrossRef]

11. Wang, D.; Teo, W.; Li, K. Removal of $\mathrm{H}_{2} \mathrm{~S}$ to ultra-low concentrations using an asymmetric hollow fibre membrane module. Sep. Purif. Technol. 2002, 27, 33-40. [CrossRef]

12. Xian, Y.; Shui, Y.; Li, M.; Pei, C.; Zhang, Q.; Yao, Y. pH-Dependent thermoresponsive poly[2-(diethylamino)ethyl acrylamide]-grafted PVDF membranes with switchable wettability for efficient emulsion separation. J. Appl. Polym. Sci. 2020, 137, 49032. [CrossRef]

13. Zhu, Z.; Kang, G.; Sun, Y.; Yu, S.; Li, M.; Xu, J.; Cao, Y. An experimental study on synthesis of glycolic acid via carbonylation of formaldehyde using PTFE membrane contactor. J. Membr. Sci. 2019, 586, 259-266. [CrossRef]

14. Koseoglu-Imer, D.Y.; Kose, B.; Altinbas, M.; Koyuncu, I. The production of polysulfone (PS) membrane with silver nanoparticles (AgNP): Physical properties, filtration performances, and biofouling resistances of membranes. J. Membr. Sci. 2013, 428, 620-628. [CrossRef] 
15. Han, L.; Young, H.; Hwi, R.; Jin, H. Preparation of an anion exchange membrane using the blending polymer of poly(ether sulfone) (PES) and poly(phenylene sulfide sulfone) (PPSS). Membr. J. 2019, 29, 155-163.

16. Zheng, P.; Liu, K.; Wang, J.; Dai, Y.; Yu, B.; Zhou, X.; Hao, H.; Luo, Y. Surface modification of polyimide (PI) film using water cathode atmospheric pressure glow discharge plasma. Appl. Surf. Sci. 2012, 259, 494-500. [CrossRef]

17. Wang, Q.; Yu, L.; Nagasawa, H.; Kanezashi, M.; Tsuru, T. High-performance molecular-separation ceramic membranes derived from oxidative cross-linked polytitanocarbosilane. J. Am. Ceram. Soc. 2020, 103, 4473-4488. [CrossRef]

18. Gong, Y.; Liu, H.; Cheng, X. Experiments of mercaptans removal from FCC gasoline by NaOH aqueous in membrane contactor. Pet. Sci. Technol. 2010, 28, 903-910. [CrossRef]

19. Volkov, A.; Tsarkov, S.; Goetheer, E.; Volkov, V. Amine-based solvents regeneration in gas-liquid membrane contactor based on asymmetric PVTMS. Pet. Chem. 2015, 55, 716-723. [CrossRef]

20. Song, H.J.; Park, S.; Kim, H.; Gaur, A.; Park, J.W.; Lee, S.J. Carbon dioxide absorption characteristics of aqueous amino acid salt solutions. Int. J. Greenh. Gas Control 2012, 11, 64-72. [CrossRef]

21. Basavaraj, D.; Shijo, T. Experimental investigation on absorption performance of nanofluids for $\mathrm{CO}_{2}$ capture. Int. J. Air-Cond. Refrig. 2020, 28. [CrossRef]

22. Chhotaray, P.K.; Biswal, S.K.; Pandey, S. Development of novel hybrid ionic fluids for efficient $\mathrm{CO}_{2}$ capture and cellulose dissolution. J. Mol. Liq. 2020, 312, 113477. [CrossRef]

23. Yan, Y.; Zhang, Z.; Zhang, L.; Ju, S. Research progress on the absorption of $\mathrm{CO}_{2}$ in flue gas by hollow fiber membrane. Nat. Gas Ind. 2014, 34, 114-123.

24. Li, Y.; Wang, L.; Hu, X.; Jin, P.; Song, X. Surface modification to produce superhydrophobic hollow fiber membrane contactor to avoid membrane wetting for biogas purification under pressurized conditions. Sep. Purif. Technol. 2018, 194, 222-230. [CrossRef]

25. Zolfaghari, A.; Mousavi, S.; Bozarjomehri, R.; Bakhtiari, F. Gas-liquid membrane contactors: Modeling study of non-uniform membrane wetting. J. Membr. Sci. 2018, 555, 463-472. [CrossRef]

26. Yan, S.; Fang, M.; Zhang, W.; Wang, S.; Xu, Z.; Luo, Z.; Cen, K. Experimental study on the separation of $\mathrm{CO}_{2}$ from flue gas using hollow fiber membrane contactors without wetting. Fuel Process. Technol. 2007, 88, 501-511. [CrossRef]

27. Keshavarz, P.; Fathikalajahi, J.; Ayatollahi, S. Analysis of $\mathrm{CO}_{2}$ separation and simulation of a partially wetted hollow fiber membrane contactor. J. Hazard. Mater. 2007, 152, 1237-1247. [CrossRef]

28. Wang, X.; Gao, J.; Zhang, J.; Zhang, X.; Guo, R. Theoretical and experimental studies on acetylene absorption in a polytetrafluoroethylene hollow-fiber membrane contactor. Chem. Eng. Technol. 2015, 38, 215-222. [CrossRef]

29. Mosadegh-Sedghi, S.; Rodrigue, D.; Brisson, J.; Iliuta, M.C. Wetting phenomenon in membrane contactors-Causes and prevention. J. Membr. Sci. 2014, 452, 332-353. [CrossRef]

30. Yin, Y.; Jeong, N.; Tong, T. The effects of membrane surface wettability on pore wetting and scaling reversibility associated with mineral scaling in membrane distillation. J. Membr. Sci. 2020, 614, 118503. [CrossRef]

31. Klaassen, R.; Jansen, A. The membrane contactor: Environmental applications and possibilities. Environ. Progress 2001, 20, 37-43. [CrossRef]

32. Rangwala, H. Absorption of carbon dioxide into aqueous solutions using hollow fiber membrane contactors. J. Membr. Sci. 1996, 112, 229-240. [CrossRef]

33. Abdolahi, H.; Seddighi, S. $\mathrm{CO}_{2}$ capture by modified hollow fiber membrane contactor: Numerical study on membrane structure and membrane wettability. Fuel Process. Technol. 2020, 209, 106530. [CrossRef]

34. Druzhinin, O.; Troitskaya, Y.; Zilitinkevich, S. The study of momentum, mass, and heat transfer in a droplet-laden turbulent airflow over a waved water surface by direct numerical simulation. J. Geophys. Res. Oceans 2018, 123, 8346-8365. [CrossRef]

35. Li, C.; Sun, W.; Lu, Z.; Ao, X.; Li, S. Ceramic nanocomposite membranes and membrane fouling: A review. Water Res. 2020, 175, 115674. [CrossRef]

36. Liu, Z.; Cao, J.; Li, C.; Meng, H. A review on cleaning of nanofiltration and reverse osmosis membranes used for water treatment. Desalin. Water Treat. 2017, 87, 27-67. [CrossRef]

37. Taheran, M.; Brar, S.K.; Verma, M.; Surampalli, R.; Zhang, T.C.; Valero, J. Membrane processes for removal of pharmaceutically active compounds (PhACs) from water and wastewaters. Sci. Total Environ. 2016, 547, 60-77. [CrossRef] 
38. Muntha, S.T.; Kausar, A.; Siddiq, M. Advances in polymeric nanofiltration membrane: A review. Polym. Plast. Technol. Eng. 2017, 56, 841-856. [CrossRef]

39. Naim, R.; Ismail, A.F.; Matsuura, T.; Rudaini, I.A.; Abdullah, S. Polyetherimide hollow fiber membranes for $\mathrm{CO}_{2}$ absorption and stripping in membrane contactor application. RSC Adv. 2018, 8, 3556-3563. [CrossRef]

40. Xu, Y.; Lin, Y.; Lee, M.; Malde, C.; Wang, R. Development of low mass-transfer-resistance fluorinated $\mathrm{TiO}_{2}$ $-\mathrm{SiO}_{2} / \mathrm{PVDF}$ composite hollow fiber membrane used for biogas upgrading in gas-liquid membrane contactor. J. Membr. Sci. 2018, 552, 253-264. [CrossRef]

41. Fang, M.; Xiang, Q.; Zhou, X.; Ma, Q.; Luo, Z. Experimental study on $\mathrm{CO}_{2}$ absorption into aqueous ammonia-based blended absorbents. Energy Procedia 2014, 61, 2284-2288. [CrossRef]

42. Chen, Z.; Shen, Q.; Gong, H.; Du, M. Preparation of a novel dual-layer polyvinylidene fluoride hollow fiber composite membrane with hydrophobic inner layer for carbon dioxide absorption in a membrane contactor. Sep. Purif. Technol. 2020, 248, 117045. [CrossRef]

43. Lee, H.; Kim, M.; Park, J. Decompression stripping of carbon dioxide from rich monoethanolamine through porous hydrophobic modified ceramic hollow fiber membrane contactor. Sep. Purif. Technol. 2020, 236, 116304. [CrossRef]

44. Koonaphapdeelert, S.; Li, K. Preparation and characterization of hydrophobic ceramic hollow fiber membrane. J. Membr. Sci. 2007, 291, 70-76. [CrossRef]

45. Lee, H.J.; Magnone, E.; Park, J.H. Preparation, characterization and laboratory-scale application of modified hydrophobic aluminum oxide hollow fiber membrane for $\mathrm{CO}_{2}$ capture using $\mathrm{H}_{2} \mathrm{O}$ as low-cost absorbent. J. Membr. Sci. 2015, 494, 143-153. [CrossRef]

46. Lee, H.J.; Park, J.H. Effect of hydrophobic modification on carbon dioxide absorption using porous alumina $\left(\mathrm{Al}_{2} \mathrm{O}_{3}\right)$ hollow fiber membrane contactor. J. Membr. Sci. 2016, 518, 79-87. [CrossRef]

47. Lee, H.J.; Park, Y.G.; Kim, M.K.; Lee, S.H.; Park, J.H. Study on $\mathrm{CO}_{2}$ absorption performance of lab-scale ceramic hollow fiber membrane contactor by gas/liquid flow direction and module design. Sep. Purif. Technol. 2019, 220, 189-196. [CrossRef]

48. Lee, H.J.; Kim, M.K.; Park, J.H.; Magnone, E.; Kim, M.K.; Park, J.H.; Magnone, E. Temperature and pressure dependence of the $\mathrm{CO}_{2}$ absorption through a ceramic hollow fiber membrane contactor module. Chem. Eng. Process. 2020, 150, 107871. [CrossRef]

49. Ogunlude, P.; Abunumah, O.; Gobina, E. A study of gas diffusion characteristics on nano-structured ceramic membranes. Eur. J. Eng. Form. Sci. Artic. 2020, 4, 21-23. [CrossRef]

50. An, L.; Yu, X.; Yang, J.; Tu, S.-T.; Yan, J. $\mathrm{CO}_{2}$ capture using a superhydrophobic ceramic membrane contactor. Energy Procedia 2015, 75, 2287-2292. [CrossRef]

51. Goh, P.S.; Lau, W.J.; Othman, M.H.D.; Ismail, A.F. Membrane fouling in desalination and its mitigation strategies. Desalination 2018, 425, 130-155. [CrossRef]

52. Xing, W.H. Membrane-Based Separations in Metallurgy; Jiang, L.Y., Li, N., Eds.; Elsevier: Amsterdam, The Netherlands, 2017; pp. 357-370.

53. Choudhury, R.R.; Gohil, J.M.; Mohanty, S.; Nayak, S.K. Antifouling, fouling release and antimicrobial materials for surface modification of reverse osmosis and nanofiltration membranes. J. Mater. Chem. A 2018, 6, 313-333. [CrossRef]

54. Zuriaga-Agustí, E.; Alventosa-Delara, E.; Barredo-Damas, S.; Alcaina-Miranda, M.; Iborra-Clar, M.; Mendoza-Roca, J. Performance of ceramic ultrafiltration membranes and fouling behavior of a dye-polysaccharide binary system. Water Res. 2014, 54, 199-210. [CrossRef] [PubMed]

55. Lee, S.J.; Dilaver, M.; Park, P.-K.; Kim, J.H. Comparative analysis of fouling characteristics of ceramic and polymeric microfiltration membranes using filtration models. J. Membr. Sci. 2013, 432, 97-105. [CrossRef]

56. Yang-Ying, Z.; Xiao-Mao, W.; Hong-Wei, Y.; Xie, Y.F. Effects of organic fouling and cleaning on the retention of pharmaceutically active compounds by ceramic nanofiltration membranes. J. Membr. Sci. 2018, 563, 734-742.

57. Xu, P.; Huang, Y.; Kong, X.; Gong, D.; Fu, K.; Chen, X.; Qiu, M.; Fan, Y. Hydrophilic membrane contactor for improving selective removal of $\mathrm{SO}_{2}$ by $\mathrm{NaOH}$ solution. Sep. Purif. Technol. 2020, 250, 117134. [CrossRef]

58. Lee, H.J.; Kim, M.K.; Lee, S.H.; Park, T.S.; Park, S.D.; Park, J.H. Integrated membrane contactor absorber/regeneration column process for $\mathrm{CO}_{2}$ capture with large scale module at various operating conditions. Catal. Today 2020, 358, 316-323. [CrossRef] 
59. Pang, H.; Chen, Z.; Gong, H.; Du, M. Fabrication of a super hydrophobic polyvinylidene fluoride-hexadecyltrimethoxysilane hybrid membrane for carbon dioxide absorption in a membrane contactor. J. Membr. Sci. 2020, 595, 117536. [CrossRef]

60. Amirabedi, P.; Akbari, A.; Yegani, R. Fabrication of hydrophobic $\mathrm{PP} / \mathrm{CH}_{3} \mathrm{SiO}_{2}$ composite hollow fiber membrane for membrane contactor application. Sep. Purific. Technol. 2019, 228, 115689. [CrossRef]

61. Ain, R.N.; Awanis, H.N.; Aroua, M.K. Supported ionic liquid membranes (SILMs) as a contactor for selective absorption of $\mathrm{CO}_{2} / \mathrm{O}_{2}$ by aqueous monoethanolamine (MEA). Sep. Purific. Technol. 2019, 230, 115849.

62. Li, C.; Thostenson, E.T.; Chou, T.W. Dominant role of tunneling resistance in the electrical conductivity of carbon nanotube-based composites. Appl. Phys. Lett. 2007, 91, 2837. [CrossRef]

63. Lu, J.; Lu, C.; Chen, Y.; Gao, L.; Zhao, X.; Zhang, H.; Xu, Z. $\mathrm{CO}_{2}$ capture by membrane absorption coupling process. Appl. Energy 2014, 115, 573-581. [CrossRef]

64. Shaikh, M.S.; Shariff, A.M.; Bustam, M.A.; Murshid, G. Physicochemical properties of aqueous solutions of sodium L-prolinate as an absorbent for $\mathrm{CO}_{2}$ removal. J. Chem. Eng. Data 2014, 59, 362-368. [CrossRef]

65. Rahmawati, Y.; Nurkhamidah, S.; Susianto, S.; Listiyana, N.; Rahmatullah, M.; HarDIan, I. Effect of Activated Alkanolamine for $\mathrm{CO}_{2}$ Absorption using Hollow Fiber Membrane Contactor. IOP Conf. Ser. Mater. Sci. Eng. 2019, 543, 12080. [CrossRef]

66. Saidi, M. Theoretical study of $\mathrm{CO}_{2}$ absorption into novel reactive 1DMA2P solvent in split-flow absorber-stripper unit: Mass transfer performance and kinetic analysis. Int. J. Chem. React. Eng. 2019, 17, 20190034. [CrossRef]

67. Feng, Z.; Fang, M.; Wang, Z.; Fan, W. Study on the absorption of $\mathrm{CO}_{2}$ by amino acid salt membrane at room temperature and the influence of absorption liquid on membrane pore structure. Boiler Technol. 2016, 47, 72-78.

68. Yan, S.; He, Q.; Zhao, S.; Wang, Y.; Ai, P. Biogas upgrading by $\mathrm{CO}_{2}$ removal with a highly selective natural amino acid salt in gas-liquid membrane contactor. Chem. Eng. Process. Process Intensif. 2014, 85, 125-135. [CrossRef]

69. Lu, J.; Ji, Y.; Zhang, H.; Chen, M. $\mathrm{CO}_{2}$ capture using activated amino acid salt solutions in a membrane contactor. Sep. Sci. Technol. 2010, 45, 1240-1251. [CrossRef]

70. Li, D. Carbon Dioxide Capture Characteristics and Reaction Kinetics of Potassium Lysine/Potassium Carbonate Composite Solution. Master's Thesis, Huaqiao University, Quanzhou, China, 2017.

71. Feng, X. Study on the Process of Arginine/Potassium Carbonate Compound Solution Absorbing Carbon Dioxide. Master's Thesis, Hebei University of Science and Technology, Shijiazhuang, Hebei, China, 2013.

72. Lu, J.; Zhang, H.; Ji, Y.; Liu, C.; Fan, F. Evaluation of $\mathrm{CO}_{2}$ gas capture performance of an amino acid salt-based composite solution. Chem. Eng. J. Chin. Univ. 2010, 24, 410-415.

73. Nii, S.; Takeuchi, H. Removal of $\mathrm{CO}_{2}$ and/or $\mathrm{SO}_{2}$ from gas streams by a membrane absorption method. Gas Sep. Purific. 1994, 8, 107-114. [CrossRef]

74. Li, Y.; Wang, L.; Zhang, Z.; Hu, X.; Cheng, Y.; Zhong, C. Carbon dioxide absorption from biogas by amino acid salt promoted potassium carbonate solutions in a hollow fiber membrane contactor: A numerical study. Energy Fuels 2018, 32, 3637-3646. [CrossRef]

75. Lu, S.; Zhao, Y.; Song, J.; Li, Y. Experimental studies of $\mathrm{CO}_{2}$ absorption enhancement in water-based nanofluids of carbon nanotubes. Braz. J. Chem. Eng. 2017, 34, 597-606. [CrossRef]

76. Golkhar, A.; Keshavarz, P.; Mowla, D. Investigation of $\mathrm{CO}_{2}$ removal by silica and CNT nanofluids in microporous hollow fiber membrane contactors. J. Membr. Sci. 2013, 433, 17-24. [CrossRef]

77. Pang, C.; Lee, J.; Kang, Y. Review on combined heat and mass transfer characteristics in nanofluids. Int. J. Therm. Sci. 2015, 87, 49-67. [CrossRef]

78. Tinge, J.; Drinkenburg, A. Absorption of gases into activated carbon-water slurries in a stirred cell. Chem. Eng. Sci. 1992, 47, 1337-1345. [CrossRef]

79. Kim, W.; Kang, H.; Jung, K.; Kim, S. Synthesis of silica nanofluid and application to $\mathrm{CO}_{2}$ absorption. Sep. Sci. Technol. 2008, 43, 3036-3055. [CrossRef]

80. Yoon, S.; Chung, J.T.; Kang, Y.T. The particle hydrodynamic effect on the mass transfer in a buoyant $\mathrm{CO}_{2}$-bubble through the experimental and computational studies. Int. J. Heat Mass Transf. 2014, 73, 399-409. [CrossRef]

81. Lee, J.K.; Koo, J.; Hong, H.; Kang, Y.T. The effects of nanoparticles on absorption heat and mass transfer performance in $\mathrm{NH}_{3} / \mathrm{H}_{2} \mathrm{O}$ binary nanofluids. Int. J. Refriger. 2010, 33, 269-275. [CrossRef] 
82. Pineda, I.T.; Lee, J.W.; Jung, I.; Kang, Y.T. $\mathrm{CO}_{2}$ absorption enhancement by methanol-based $\mathrm{Al}_{2} \mathrm{O}_{3}$ and $\mathrm{SiO}_{2}$ nanofluids in a tray column absorber. Int. J. Refriger. 2012, 35, 1402-1409. [CrossRef]

83. Lee, J.W.; Kang, Y.T. $\mathrm{CO}_{2}$ absorption enhancement by $\mathrm{Al}_{2} \mathrm{O}_{3}$ nanoparticles in $\mathrm{NaCl}$ aqueous solution. Energy 2013, 53, 206-211. [CrossRef]

84. Krishnamurthy, S.; Bhattacharya, P.; Phelan, P.E.; Prasher, R.S. Enhanced mass transport in nanofluids. Nano Lett. 2006, 6, 419-423. [CrossRef]

85. Ansaripour, M.; Haghshenasfard, M.; Moheb, A. Experimental and numerical investigation of $\mathrm{CO}_{2}$ absorption using nanofluids in a hollow fiber membrane contactor. Chem. Eng. Technol. 2017, 41, 367-378. [CrossRef]

86. Olle, B.; Bucak, S.; Holmes, T.C.; Bromberg, L.; Hatton, T.A.; Wang, D.I.C. Enhancement of oxygen mass transfer using functionalized magnetic nanoparticles. Ind. Eng. Chem. Res. 2006, 45, 4355-4363. [CrossRef]

87. Lu, S.; Xing, M.; Sun, Y.; Dong, X. Experimental and theoretical studies of $\mathrm{CO}_{2}$ absorption enhancement by nano- $\mathrm{Al}_{2} \mathrm{O}_{3}$ and carbon nanotube particles. Chin. J. Chem. Eng. 2013, 21, 983-990. [CrossRef]

88. Khan, U.; Zaib, A.; Khan, I.; Baleanu, D.; Nisar, K.S. Enhanced heat transfer in moderately ionized liquid due to hybrid $\mathrm{MoS}_{2} / \mathrm{SiO}_{2}$ nanofluids exposed by nonlinear radiation: Stability analysis. Crystals 2020, 10, 142. [CrossRef]

89. Wang, Z.; Fang, M.; Yan, S.; Yu, H.; Wei, C.-C.; Luo, Z. Optimization of Blended Amines for $\mathrm{CO}_{2}$ Absorption in a Hollow-Fiber Membrane Contactor. Ind. Eng. Chem. Res. 2013, 52, 12170-12182. [CrossRef]

90. Sema, T.; Naami, A.; Fu, K.; Chen, G. Comprehensive mass transfer and reaction kinetics studies of a novel reactive 4-diethylamino-2-butanol solvent for capturing $\mathrm{CO}_{2}$. Chem. Eng. Sci 2013, 100, 183-194. [CrossRef]

91. Cao, F.; Gao, H.; Gao, G.; Liang, Z. Mass transfer performance and correlation for $\mathrm{CO}_{2}$ absorption into aqueous 1-Dimethylamino-2-propanol (1DMA2P) solution in a PTFE hollow fiber membrane contactor. Chem. Eng. Process. Process Intensif. 2019, 136, 226-233. [CrossRef]

92. Mohsin, H.M.; Shariff, A.M.; Johari, K. 3-Dimethylaminopropylamine (DMAPA) mixed with glycine (GLY) as an absorbent for carbon dioxide capture and subsequent utilization. Sep. Purif. Technol. 2019, 222, 297-308. [CrossRef]

93. Talavari, A.; Ghanavati, B.; Azimi, A.; Sayyahi, S. Preparation and characterization of PVDF-filled MWCNT hollow fiber mixed matrix membranes for gas absorption by $\mathrm{Al}_{2} \mathrm{O}_{3}$ nanofluid absorbent via gas-liquid membrane contactor. Chem. Eng. Res. Des. 2020, 156, 478-494. [CrossRef]

94. Jin, P.; Huang, C.; Shen, Y.; Zhan, X.; Hu, X.; Wang, L.; Wang, L. Simultaneous separation of $\mathrm{H}_{2} \mathrm{~S}$ and $\mathrm{CO}_{2}$ from biogas by gas-liquid membrane contactor using single and mixed absorbents. Energy Fuels 2017, 31, 11117-11126. [CrossRef]

95. Eslami, S.; Mousavi, S.; Danesh, S.; Banazadeh, H. Modeling and simulation of $\mathrm{CO}_{2}$ removal from power plant flue gas by PG solution in a hollow fiber membrane contactor. Adv. Eng. Softw. 2011, 42, 612-620. [CrossRef]

96. Gómez-Coma, L.; Garea, A.; Irabien, A. Mass Transfer Analysis of $\mathrm{CO}_{2}$ Capture by PVDF Membrane Contactor and Ionic Liquid. Chem. Eng. Technol. 2017, 40, 678-690. [CrossRef]

97. Zhang, G. Research on New Hydrophobic Hollow Fiber Membrane Structured Packing and Its Distillation Separation Mechanism and Characteristics. Ph.D. Thesis, Zhejiang University, Zhejiang, China, 2007.

98. Yang, Z.; Zhang, G.; Lin, L.; Ren, D.; Meng, Q.; Zhang, H. Effects of baffles on separation of aqueous ethanol solution with hollow fibers. Front. Chem. Eng. China 2009, 3, 68-72. [CrossRef]

99. Zhang, Z. A New Type of Membrane Contactor for Wastewater Deamination and Organic Acid Removal from Straw Acid Hydrolysate. Master's Thesis, Tianjin University, Tianjin, China, 2016.

100. Wang, S.; Hawboldt, K.; Abdi, M.A. Novel dual-membrane gas-liquid contactors: Modelling and concept analysis. Ind. Eng. Chem. Res. 2006, 45, 7882-7891. [CrossRef]

101. Zhang, Z. The Absorption and Separation Performance of $\mathrm{CO}_{2}$ in Hollow Fiber Membranes and Its Adsorption Characteristics in PVA Promoting Transfer Membranes. Ph.D. Thesis, Chongqing University, Chongqing, China, 2015.

102. Qazi, S.; Gómez-Coma, L.; Albo, J.; Druon-Bocquet, S.; Irabien, A.; Sanchez-Marcano, J. CO 2 capture in a hollow fiber membrane contactor coupled with ionic liquid: Influence of membrane wetting and process parameters. Sep. Purif. Technol. 2020, 233, 115986. [CrossRef]

103. Azari, A.; Abbasi, M.A.; Sanaeepur, H. CFD study of $\mathrm{CO}_{2}$ separation in an HFMC: Under non-wetted and partially-wetted conditions. Int. J. Greenh. Gas Control 2016, 49, 81-93. [CrossRef] 
104. McLeod, A.; Jefferson, B.; McAdam, E. The multiple benefits of high concentration electrolyte in chemisorption using a micro-porous hollow fibre membrane contactor (HFMC). Procedia Eng. 2012, 44, 953-954. [CrossRef]

105. Tahvildari, K.; Razavi, S.; Tavakoli, H.; Mashayekhi, A.; Golmohammadzadeh, R. Modeling and simulation of membrane separation process using computational fluid dynamics. Arab. J. Chem. 2016, 9, 72-78. [CrossRef]

106. Nakhjiri, A.T.; Heydarinasab, A.; Bakhtiari, O.; Mohammadi, T. The effect of membrane pores wettability on $\mathrm{CO}_{2}$ removal from $\mathrm{CO}_{2} / \mathrm{CH}_{4}$ gaseous mixture using $\mathrm{NaOH}$, MEA and TEA liquid absorbents in hollow fiber membrane contactor. Chin. J. Chem. Eng. 2018, 26, 1845-1861. [CrossRef]

107. Saidi, M. Mathematical modeling of $\mathrm{CO}_{2}$ absorption into novel reactive DEAB solution in hollow fiber membrane contactors; kinetic and mass transfer investigation. J. Membr. Sci. 2017, 524, 186-196. [CrossRef]

108. Zhang, Z.; Yan, Y.; Zhang, L.; Chen, Y.; Ran, J.; Pu, G.; Qin, C. Theoretical study on $\mathrm{CO}_{2}$ absorption from biogas by membrane contactors: Effect of operating parameters. Ind. Eng. Chem. Res. 2014, 53, 14075-14083. [CrossRef]

Publisher's Note: MDPI stays neutral with regard to jurisdictional claims in published maps and institutional affiliations.

(C) 2020 by the authors. Licensee MDPI, Basel, Switzerland. This article is an open access article distributed under the terms and conditions of the Creative Commons Attribution (CC BY) license (http://creativecommons.org/licenses/by/4.0/). 